\title{
A comparative approach on the impact of diet and physical activity on young people between 19 and 26 years
}

\author{
CONSTANTINESCU Mihai ${ }^{1}$, VIZITIU Elena ${ }^{1}$
}

Editor: Mihail HOTETEU, Romanian Association of Balneology, hoteteu@yahoo.com

Reviewers: Constantin Munteanu and Gabriela Dogaru

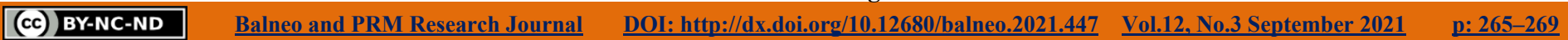

*Corresponding author: CONSTANTINESCU Mihai, E-mail: mihaic@usv.ro;

${ }^{1}$ Faculty of Physical Education and Sport, "Ștefan cel Mare” University of Suceava

\begin{abstract}
Introduction. In the literature, nutrition is considered to be the basis for the energy supply in all the forms of physical activity. Energy needs depend on gender, age, body weight and possibly the type of the physical activity. Inadequate energy intake can lead to weight loss, fatigue, lack of concentration and no athletic performance. The constant physical activity involves the consumption of carbohydrates, useful for the formation and storage of muscle glycogen. The development of healthy eating and physical activity behaviors in childhood and adolescence are very important for adult life. That is why an early intervention can lead to healthy behaviors and it can prevent the occurrence of overweight and obesity.

Objectives. The purpose of this study was to demonstrate how important a controlled diet is correlated with regular physical activity, in the normal development of young people aged between 19 and 26 years.

Conclusions. The attitude is the one that should lead to a food program with a balanced diet that ensures good health, without increasing the percentage of fat, and to cause a weight loss for the young people who want to lose weight.
\end{abstract}

Keywords: impact, diet, physical activity, young people,

\section{INTRODUCTION}

If we want to achieve the proposed objectives, we must understand how to choose foods adapted to the young people's needs. In the literature, the physical effort is a necessity of nutrients, whereas the results can be good or bad according to the intake of nutrients that we generally give to our bodies.

For this purpose, carbohydrates are considered a fuel for exercises done with medium to high intensity. An amount of carbohydrates below $40 \%$ of the total energy can lead to fatigue or exhaustion, due to the decrease of glycogen stores. The protein requirement is according to the body mass, intensity and type of physical activity. The protein intake is useful for strength and endurance disciplines in which the muscle glycogen reserve is depleted. Fats are also considered a source of energy whereas their consumption depends on the intensity and type of physical activity and also on the amount of glycogen present. Another useful nutrient in the physical activity is water. The loss of $1 \%$ of the body weight can lead to decreased exercise capacity. (1)

If we talk about minerals, magnesium is one of the essential nutrients for living organisms, it has a prophylactic role for various diseases and at the same time an enzymatic cofactor for over 300 reactions. Magnesium is involved in muscle contraction, in regulating blood pressure and in keeping the vasomotor tone. In children and teenagers, the serum magnesium concentration is different according to the established reference intervals, with small deviations, by age groups, as the data found in the literature (2).

Another important element is calcium. The skeleton contains about $99 \%$ of the total calcium in the body, whereas the rest is found in the blood plasma and extracellular fluid. Along with magnesium, calcium is important in the muscle contraction, normal heart activity and enzymatic processes. Therefore, reducing the amount of calcium through increased metabolic intake and inadequate diet intake can influence cardiac excitability but also enzymatic processes. It is important to determine the total serum calcium that is achieved mainly by the colorimetric method and there are useful reference intervals for a correct interpretation of laboratory results, but also for the clinicians' activity. Calcium deficiency can lead to poor infant development and later on to rickets (3). Iron is part of the essential trace elements whereas the human body has a content of 3-4 g of iron. Most of this amount is found in hemoglobin, whose function is to transport oxygen and carbon dioxide between lungs and tissues, as well as to regulate blood $\mathrm{pH}$. The balance between the two oxidation states $(\mathrm{Fe} 2+$ and $\mathrm{Fe} 3+)$ is very important for biological systems that use iron in metabolic processes (4).

Gillson's study in 2006 found that exercise plays a role in the prevention of obesity in teenagers. Furthermore, the study evaluates the effects of exercise objectives, the behavior of young people to exercise in their free time. (5) 
In a study published in 2011, Gillison (6) points out the factors that motivated girls to exercise. Most of the study participants reported that they were more interested in their health during the study, but also in the future. One of the problems faced by the study participants was weight control. On the other hand, the girls showed that exercise was an opportunity to achieve their personal goal and it gave them a sense of competition and achievement.

Another study published in 2011 (7) reveals that there is a relationship between adolescents' self-perception of body weight and motivation to exercise, especially in their free time.

For teenagers as well as for young people, the development of a healthy diet and physical activity are important for the future adult. An important role is played by parents and teachers who can influence the young people's behavior in terms of health, prevention of overweight, obesity and sedentary lifestyle (8).

Poor diet and insufficient physical activity are considered important independent risk factors for the development of cardiovascular and neurological diseases, but also for obesity. They are the main factors that contribute to the global burden of disease. $(9,10)$

Recent research suggests that a low-nutrient diet is responsible for more deaths globally than any other risk factor, including the use of tobacco (10). Therefore, eating and physical activity behaviors can be identified as priority areas for public health actions. $(11,12)$. These behaviors develop in childhood, so children and teenagers can be considered target population groups for prophylaxis (12).

The World Health Organization (WHO) recommended the consumption of at least 400 grams of fruits and vegetables per day, which is the equivalent to five servings of 80 grams, in order to prevent chronic diseases. However, about $78 \%$ of the world's population does not consider this recommendation (13). There are studies showing that there is evidence linking increased intake of whole grains, nuts and seeds to the reduced risk of cardiovascular disease and type 2 diabetes $(14,15)$, whereas the low consumption of these foods is still widespread $(10,16)$. In 2017, the low intake of whole grains was a major food risk factor for mortality among women and the second most important risk factor for mortality among men. Among the dietary factors that are associated with health benefits we can mention omega-3 fatty acids from seafood, fiber, polyunsaturated fatty acids, milk and calcium (10)

It is recommended to reduce the intake of sodium, red meat and especially processed meat, as well as trans fats and sugary drinks; they are part of the recommendations to promote the population's health and to prevent the occurrence of chronic diseases (10). Physical activity is associated with health benefits (17), especially protection against cardiovascular diseases (18), type 2 diabetes and certain types of cancer. However, globally, approximately $31 \%$ of adults and $80 \%$ of adolescents do not consider the minimum recommendations for physical activity (19). Tremblay's study (20) of 15 countries with high, middle and low income shows that no country had at least $80 \%$ of children and teenagers who pay attention to the physical activity guidelines. Insufficient physical activity means more than 5.3 million deaths per year or $9 \%$ of premature mortality (17). Even for the physically active persons, the prolonged sedentary behavior may be associated with an increased risk of type 2 diabetes or with a cardiovascular disease. (21,22). Globally, the prevalence of obesity among children and teenagers has increased in recent decades $(23,24,25,26)$, whereas the causes are a change in diet (food, meat and highly processed dairy products), in addition to the increased sedentary behavior (27).

In countries with low and middle income, adolescents in the richest households seem to be the most sedentary ones (28), which may be due to the fact that lower socioeconomic groups have to walk or ride a bike as transport, and this is why they are more likely to work in physically demanding jobs, such as farm or factory. For many young people, obesity can coexist with malnutrition or micronutrient deficiencies (29). Overweight in childhood and adolescence can be associated with short- and longterm health risks and poor quality of life $(30,31)$. Each organ can be negatively affected by excess body weight, especially the cardiovascular, metabolic, skeletal systems $(31,32)$.

Excess adiposity in childhood can negatively influence the pubertal development in boys and girls (33). Furthermore, overweight children and teenagers may experience psychological comorbidities (anxiety, depression), externalization disorders (e.g., impulsivity, attention deficit hyperactivity disorder), sleep problems and uncontrolled eating $(32,34)$.

The purpose of this study was to demonstrate how important is a controlled diet correlated with physical activity in the normal development of young people aged $19-26$.

\section{Material and method:}

The current study is of longitudinal type and took place over a period of 6 months at "Ștefan cel Mare" University of Suceava. A number of 90 young people were studied and divided into two groups. The first group (experiment) included young people who did physical activities constantly and who were registered at sports clubs. The second (control) group included young people who occasionally got into physical activities.

The inclusion criteria in the study were the following: the age between 19 and 26, young people studying at "Ștefan cel Mare" University of Suceava, their consent to participate in the study and without chronic diseases.

In addition to demographic data (gender, age, living environment), both groups were assessed the body mass 
index, as well as physiological parameters such as heart rate, blood pressure (parameters that show the ability to adapt to exercise of the tested person), peripheral blood saturation in oxygen (oximetric method). The level of oxygen in the blood is the percentage of oxygen that is carried by red blood cells. Normal values of oxygen level are considered to be between $95-100 \%$. The initial and final assessments were made in the physiotherapy room where there is an appropriate temperature that does not influence the sensor and implicitly the measurement. For the accuracy of the obtained results, the pulse oximeter for the index was applied, whereas for female students, the nail polish applied on the finger or the false nail was removed. The pulse oximeter was used for this parameter, a device that measures peripheral oxygen saturation ( $\mathrm{Sp}$ O2) and the pulse. Blood oxygen saturation was thus monitored, whereas the accuracy for measurement was \pm $2 \%$ for pulse and $\pm 2 \%$ for oxygen. Blood pressure with the two components (systolic and diastolic pressure) was assessed by using the sphygmomanometer.

The assessment was made over a period of 21 days whereas the measurements were made on the first and last day. Thalliometer, sphygmomanometer, pulse oximeter were used.

The experiment group (Group 1) included 45 young people with the average age of 23 , of which 22 males and 23 females, who played volleyball, handball, who went swimming, who did athletics and other sports with daily physical training (including twice a day). The diet was controlled from a nutritional point of view and included all the dietary principles adapted to the type of effort and for its intensity of execution.

The control group (Group 2) also consisted of 45 young people (with the average age of 23 years), 22 males and 23 females, who did moderate physical activities and went to the gym twice a week. The diet was not controlled, each of the young people chose the food principles necessary for their own needs.

\section{Results and discussions:}

At the final assessment, the body mass index registered a decrease of $0.67 \%$ in the experiment group in comparison to $0.52 \%$ in the control group.

Chart no. 1. The evolution of the body mass index

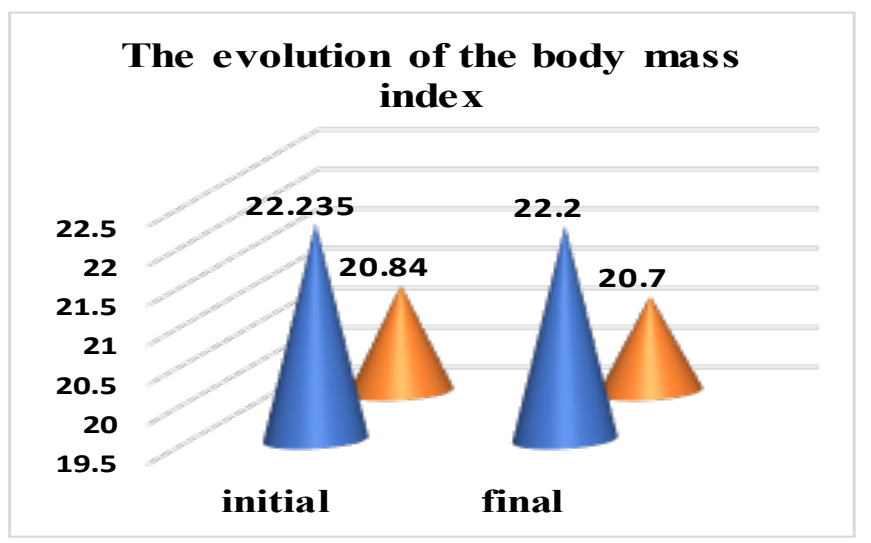

The systolic blood pressure (SBP) remained unchanged in the experiment group, but in the control group there was an increase of $4.17 \%$.

Chart no. 2. The evolution of the systolic and diastolic blood pressure

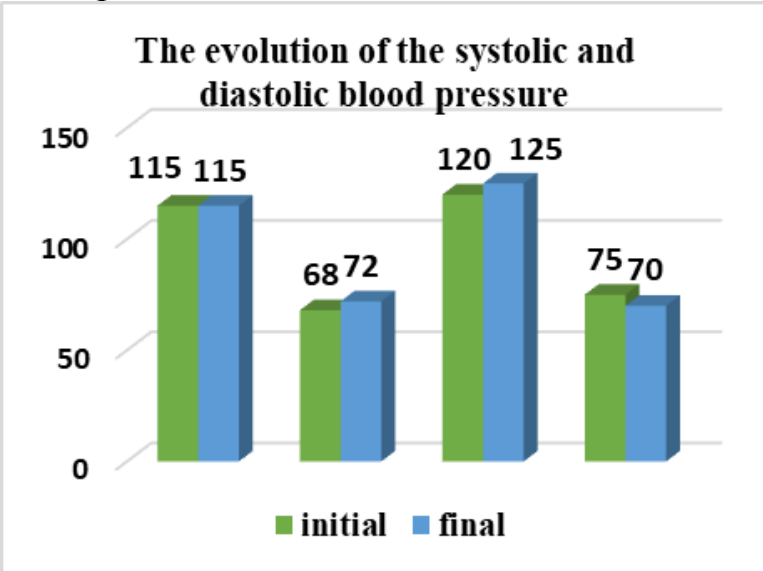

At the final assessment, the diastolic blood pressure (DBP) increased by $5.88 \%$ in the experiment group, in comparison to an increase of $11.43 \%$ in the control group. The heart rate (HR) changed in both groups and registered at the final assessment a decrease of $1.96 \%$ in the experiment group and $6.67 \%$ in the control group.

Graph no. 3. Evolution of heart rate and oxygen saturation

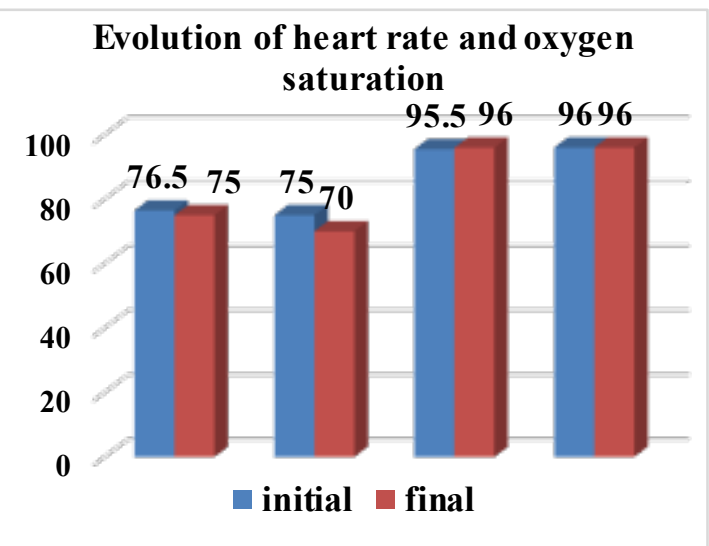

As for the oxygen saturation (OS), the obtained results indicate an increase of $0.52 \%$ in the experiment group, but it remained unchanged in the control group.

Table no. 1. Parameters of study groups

\begin{tabular}{|c|c|c|c|c|}
\hline Group & \multicolumn{2}{|c|}{ Experiment group } & \multicolumn{2}{|c|}{ Control group } \\
\hline $\begin{array}{l}\text { Parameters/ } \\
\text { moment }\end{array}$ & initial & final & initial & final \\
\hline BMI & $22.31 \pm 4.25$ & $22.2 \pm 4.26$ & $20.84 \pm 5.17$ & $20.7 \pm 5.15$ \\
\hline SBP & $115 \pm 7.66$ & $115 \pm 7.01$ & $120 \pm 7.89$ & $125 \pm 7.02$ \\
\hline DBP & $68 \pm 7.59$ & $72 \pm 6.07$ & $70 \pm 8.62$ & $78 \pm 5.26$ \\
\hline HR & $76.5 \pm 13.31$ & $75 \pm 9.08$ & $75 \pm 10.94$ & $70 \pm 7.79$ \\
\hline OS & $95.5 \pm 2.76$ & $96 \pm 1.63$ & $96 \pm 1.87$ & $96 \pm 1.72$ \\
\hline
\end{tabular}




\section{Discussions}

In young people who did physical activities constantly, with a diet controlled by a nutritionist, the followed parameters did not register large changes, in comparison to the control group, which showed changes in parameters, the consequence of adaptation to effort.

- Body mass index decreased in both groups of students, a result correlated with physical activity

- Heart rate, pulse and blood pressure were influenced by physical activity and daily training. The increase in blood pressure and the heart rate was higher in the control group. The constant physical activities enabled the adaptation of these parameters to efforts in time. Therefore there were no high values of blood pressure or heart rate in the experiment group.

- Oxygen saturation of the blood increased only in the experimental group that did constant physical activities, due to the ability to adapt to effort, which is consistent with specialized studies.

\section{Conclusions}

- Regular, moderate-intensity physical activity can keep physical and mental health, especially in the 19-26 age group, in our case, students.

- The evolution of the parameters heart rate, blood pressure, oxygen saturation was better in young people who did regular physical activities.

- The effects of regular physical activities of moderate intensity may reduce the risk of morbidity and mortality for the studied age group.

- It is important to learn healthy eating habits and physical activity at an early age; they will have beneficial effects in adulthood, certainly preventing obesity.

- In order to achieve this goal, young people should follow a diet with a balanced contents of carbohydrates, proteins and lipids, because carbohydrates are the body's energy source, whereas the young people who play sports need a diet rich in healthy sources of carbohydrates, such as oats, brown rice, whole wheat pasta, buckwheat, soy, fruits and vegetables.

\section{Author contributions.}

All the authors had the same contribution.

\section{Accordance to ethics standards.}

The study complies with the rules of ethics and deontology according to the legislation in force

\section{REFERENCES:}

1. Silisteanu SC, Covasa M. The importance of nutrition and physical activity in young people increased quality of life.The 5th IEEE International Conference on E-Health and Bioengineering - EHB 2015, Grigore T. Popa University of Medicine and Pharmacy, Iasi, Romania, November 19-21, 2015, 978-1-4673-7545-0/15

2. Antonescu E, Bota G, Serb B, Atasie D, Dahm Tataru C, Totan M, Duica L, Silisteanu SC, Szakacs J, Arghir OC, Oswald I, Manea MM. Study of the Total Serum Concentration of Serrum Ionized Magnesium in Children and Adolescents from Sibiu Area. Rev. Chimie (Bucharest), 69(12), $2018 \mathrm{http}: / /$ www.revistadechimie.ro

3. Antonescu E, Totan M, Boitor GC, Szakaks J, Silisteanu SC, Fleaca SR, Cernusca Mitariu S, Serb BH. The Reference Intervals Used in Pediatric Medical Analysis Laboratories to Interpret the Results Analysis for Total Serum Calcium, Rev. Chimie (Bucharest), 68 (2), 2017, 243-245

4. Totan M, Antonescu E, Gligor FG. Quantitative Spectrophotometric Determinations of $\mathrm{Fe} 3+$ in Iron Polymaltose Solution, Indian Journal Pharmaceutical Sciences, DOI: 10.4172/pharmaceutical-sciences.1000354

5. Gillison FB, Standage M, Skevington SM. Relationships among adolescents' weight perceptions, exercise goals, exercise motivation, quality of life and leisure-time exercise behaviour: a self-determination theory approach. Health Educ Res.Dec;21(6):836-47. Epub 2006

6. Gillison F, Sebire S, Standage M. What motivates girls to take up exercise during adolescence? Learning from those who succeed. British Journal of Health Psychology, 28 September 2011, https://doi.org/10.1111/j.2044-8287.2011. 02053.X

7. Gillison FB, Standage M, Suzanne M, Skevington M. Motivation and Body-Related Factors as Discriminators of Change in Adolescents' Exercise Behavior Profiles. Journal of Adolescent Health, 48 (1),2011, 44-51

8. Morgan EH, Schoonees A, Sriram U, Faure $\mathrm{M}$, Seguin-Fowler RA. Caregiver involvement in interventions for improving children's dietary intake and physical activity behaviors. Cochrane Database Syst Rev. 2020 Jan; 2020(1): $\quad$ CD012547. doi: 10.1002/14651858.CD012547.pub2

9. Forouzanfar MH, Afshin A, Alexander L, Anderson HR, Bhutta, ZA, Biryukov S, et al. Global, regional, and national comparative risk assessment of 79 behavioural, environmental and occupational, and metabolic risks or clusters of risks, 1990-2015: a systematic analysis for the Global Burden of Disease Study 2015. Lancet 2016;388(10053):1659-724. 10.1016/S0140-6736(16)31679-8;

10. GBD 2017 Diet Collaborators. Health effects of dietary risks in 195 countries, 1990-2017: a systematic analysis for the Global Burden of Disease Study 2017. The Lancet 2019; 393(10184): 1958-72. (DOI: 10.1016/S01406736(19)30041-8; PUBMED: 30954305)

11. Beaglehole R, Bonita R, Horton R, Adams C, Alleyne G, Asaria $\mathrm{P}$, et al. Priority actions for the non-communicable disease crisis. Lancet 2011;377(9775):1438-47. (DOI: 10.1016/S0140-6736(11)60393-0) 
12. World Health Organization. Report of the Commission on Ending Childhood Obesity. Geneva: World Health Organization, 2016

13. Hall JN, Moore S, Harper SB, Lynch JW. Global variability in fruit and vegetable consumption. American Journal of Preventative Medicine 2009;36(5):402-9.e5.

(DOI: 10.1016/j.amepre.2009.01.029;).

14. Afshin A, Micha R, Khatibzadeh S, Mozaffarian D. Consumption of nuts and legumes and risk of incident ischemic heart disease, stroke, and diabetes: a systematic review and meta-analysis. American Journal of Clinical Nutrition 2014;100(1):278-88.

(DOI: 10.3945/ajen.113.076901

15. Ye EQ, Chacko SA, Chou EL, Kugizaki M, Liu S. Greater whole-grain intake is associated with lower risk of type 2 diabetes, cardiovascular disease, and weight gain. Journal of Nutrition 2012; 142(7): 1304-13. $\quad$ (DOI: 10.3945/jn.111.155325

16. Micha R, Khatibzadeh S, Shi P, Andrews KG, Engell RE, Mozzaffarian D, Global Burden of Diseases Nutrition and Chronic Diseases Expert Group (NutriCoDE). Global, regional, and national consumption of major food groups in 1990 and 2010: a systematic analysis including 266 country-specific nutrition surveys worldwide. BMJ Open 2015;5(9):e008705.

17. Lee IM, Shiroma EJ, Lobelo F, Puska P, Blair SN, Katzmarzyk PT, for the Lancet Physical Activity Series Working Group. Effect of physical inactivity on major non-communicable diseases worldwide: an analysis of burden of disease and life expectancy. Lancet 2012; 380 (9838):219-29. (DOI: 10.1016/S0140-6736(12)61031-9)

18. Sofi F, Capalbo A, Cesari F, Abbate R, Gensini GF. Physical activity during leisure time and primary prevention of coronary heart disease: an updated meta-analysis of cohort studies. European Journal of Cardiovascular Prevention

Rehabilitation 2008;15(3):247-57. 10.1097/HJR.0b013e3282f232ac;

(DOI:

19. Hallal PC, Andersen LB, Bull FC, Guthold R, Haskell W, Ekelund U, for the Lancet Physical Activity Series Working Group. Global physical activity levels: surveillance progress, pitfalls, and prospects. Lancet 2012;380(9838):247-57. (DOI: 10.1016/S0140-6736(12)60646-1)

20. Tremblay MS, Gray CE, Akinroye K, Harrington DM, Katzmarzyk PT, Lambert EV, et al. Physical activity of children: a global matrix of grades comparing 15 countries. Journal of Physical Activity and Health 2014;11(Suppl 1):S113-25. (DOI: 10.1123/jpah.2014-0177

21. Biswas A, Oh PI, Faulkner GE, Bajaj RR, Silver MA, Mitchell MS, et al. Sedentary time and its association with risk for disease incidence, mortality, and hospitalization in adults: a systematic review and meta-analysis. Annals of Internal Medicine 2015; 162(2):123-32. (DOI: 10.7326/M14-1651)

22. Wilmot EG, Edwardson CL, Achana FA, Davies MJ, Gorely $\mathrm{T}$, Gray LJ, et al. Sedentary time in adults and the association with diabetes, cardiovascular disease and death: systematic review

and meta-analysis. Diabetologia 2012;55(11): 2895-905. (DOI: 10.1007/s00125-012-2677-z; PUBMED: 22890825)
23. Black RE, Victora CG, Walker SP, Bhutta ZA, Christian P, Onis $M$, et al. Maternal and child undernutrition and overweight in low-income and middle-income countries. Lancet 2013;382 (9890): 427-51. (DOI: 10.1016/S0140-6736(13)60937-X)

24. Onis M, Blössner M, Borghi E. Global prevalence and trends of overweight and obesity among preschool children. American Journal of Clinical Nutrition 2010;92(5): 1257-64. (DOI: 10.3945/ajen.2010.29786;

25. Lobstein T, Jackson-Leach R, Moodie ML, Hall KD, Gortmaker SL, Swinburn BA, et al. Child and adolescent obesity: part of a bigger picture. Lancet 2015; 385(9986): 2510-20. (DOI: 10.1016/S0140-6736(14) 61746-3)

26. Ng M, Fleming T, Robinson M, Thomson B, Graetz N, Margono $\mathrm{C}$, et al. Global, regional, and national prevalence of overweight and obesity in children and adults during 1980-2013: a systematic analysis for the Global Burden of Disease Study 2013. Lancet 2014;384(9945):766-81. (DOI: 10.1016/S0140-6736(14)60460-8)

27. Popkin BM, Adair LS, Ng SW. Now and then: the global nutrition transition: the pandemic of obesity in developing countries. Nutrition Reviews 2013;70(1):3-21.

28. 28. Mielke GI, Brown WJ, Nunes BP, Silva ICM, Hallal PC. Socioeconomic correlates of sedentary behavior in adolescents: systematic review and meta-analysis. Sports Medicine 2017;47(1):61-75. (DOI: 10.1007/s40279-0160555-4; PUBMED: 27260683)

29. Tzioumis E, Adair LS. Childhood dual burden of under- and overnutrition in low- and middle-income countries: a critical review. Food and Nutrition Bulletin 2014; 35(2):230-43. (PMC4313560; PUBMED: 25076771)

30. Buttitta M, Iliescu C, Rousseau A, Guerrien A. Quality of life in overweight and obese children and adolescents: a literature review. Quality of Life Research 2014;23(4): 1117-39. (DOI: 10.1007/s11136-013-0568-5

31. Daniels SR. Complications of obesity in children and adolescents. International Journal of Obesity 2009;33(Suppl 1):S60-5. (DOI: 10.1038/ijo.2009.20; PUBMED: 19363511)

32. Pulgarón ER. Childhood obesity: a review of increased risk for physical and psychological co-morbidities. Clinical Therapeutics 2014;35(1):A18-32. (DOI: 10.1016/ j.clinthera. 2012.12.014; PUBMED: 21151145)

33. Solorzano CMB, McCartney CR. Obesity and the pubertal transition in girls and boys. Reproduction 2010;140(3):399-410. (DOI: 10.1530/REP-100119). 